\title{
Association of High-Density Lipoprotein Subclasses with Carotid Intima-Media Thickness: Shimane CoHRE Study
}

\author{
Yoshitomo Notsu ${ }^{1}$, Shozo Yano ${ }^{1,4}$, Miwako Takeda ${ }^{4}$, Masayuki Yamasaki ${ }^{2,4}$, Minoru Isomura ${ }^{3,4}$, \\ Toru Nabika ${ }^{3,4}$ and Atsushi Nagai ${ }^{1}$ \\ ${ }^{1}$ Department of Laboratory Medicine, Shimane University, Izumo, Japan \\ ${ }^{2}$ Department of Environmental and Preventive Medicine, Shimane University, Izumo, Japan \\ ${ }^{3}$ Department of Functional Pathology, Faculty of Medicine, Shimane University, Izumo, Japan \\ ${ }^{4}$ The Center for Community-based Healthcare Research and Education (CoHRE), Shimane University, Izumo, Japan
}

Aims: Recent studies suggested that subclasses of high-density lipoprotein (HDL) may be a better biomarker to predict the risk of atherosclerotic disorders. We aimed to examine the association of HDL2- and HDL3-cholesterol (HDL2-C and HDL3-C) with carotid intima-media thickness (IMT) using a new method to quantify the HDL-C subclasses.

Methods: Participants were 657 Japanese subjects ( 434 women) who received a health examination (mean age: 73 years). Serum samples were analyzed by the homogenous assay for HDL-C and HDL3-C. HDL2-C was calculated indirectly by subtracting HDL3-C from HDL-C. HDL3-C measured by this assay was well correlated with that measured by ultracentrifugation $(r=0.898, p<$ 0.001). The maximum IMT (max-IMT) and plaque score (PS) were evaluated by ultrasonography following the standard protocol.

Results: HDL3-C was associated with age both in men $(r=-0.322, p<0.0001)$ and women $(r=-0.315$, $p<0.0001)$. In a simple regression analysis, max-IMT showed an inverse association with HDL3-C, whereas no significant association was observed with HDL2-C. A multiple linear regression analysis indicated, however, that the association between HDL3-C and max-IMT was not significant in both aged and younger populations when age was included in the analysis. Further, not only HDL2-C but also HDL3-C was not a significant predictor of 'atherosclerotic arteries' defined as the max-IMT $\geq 1.5 \mathrm{~mm}$. Similar results were observed in the analysis on PS.

Conclusions: Neither HDL3-C nor HDL2-C was significantly associated with carotid atherosclerosis in the Japanese population in this study.

\section{See editorial vol. 25: 40-41}

Key words: High-density lipoprotein (HDL), Cholesterol, Atherosclerosis, Intima-media thickness (IMT)

\section{Introduction}

A high level of plasma HDL-C has long been believed to associate with a reduced number of cardiovascular events in general populations as well as in populations with high risks for cardiovascular events $^{1-8)}$. However, this concept is now controversial

Address for correspondence: Shozo Yano, Department of Laboratory Medicine, Shimane University Faculty of Medicine, 89-1 Enya-cho, Izumo, Shimane 693-8501, Japan

E-mail: syano@med.shimane-u.ac.jp

Received: November 8, 2016

Accepted for publication: March 14, 2017 because of recent evidence against the beneficial role of $\mathrm{HDL}^{9-12)}$. In this context, it was of interest that a recent cohort study suggested that two HDL-C subclasses, HDL2 and 3, had opposite effects on the plaque formation; an inverse association between HDL3-C and plaque area and a positive association between HDL2-C and plaque thickness were found in the US population ${ }^{13)}$.

In spite of increasing attention to physiological roles of the HDL subclasses, a limited number of reports have so far been available on the role of the HDL-C subclasses in cardiovascular diseases probably due to methodological difficulty in quantification of 
the subclasses ${ }^{1,14-17)}$; it is necessary to separate the two HDL subclasses by ultracentrifugation [HDL2 (1.0631.125) and HDL3 (1.125-1.210)] ${ }^{18-20)}$. Measurement of plasma concentration of HDL subclasses was therefore a laborious and time-consuming process, which hampers quantification of HDL2 and HDL3 in largescale clinical and epidemiological studies. In this context, it was groundbreaking that a novel reagent was introduced to separate HDL2 from HDL3, which made it possible to quantify them using a versatile automatic analyzer without ultracentrifugation ${ }^{21)}$. Further, a new assay kit was recently developed and kindly provided (Kyowa Medex Co., Ltd. Tokyo, Japan), which established a simple method to determine precise concentrations of HDL2-C and HDL3-C ${ }^{22}$.

In this study, we therefore employed the new method and examined the association of HDL2-C and HDL3-C with the intima-media thickness (IMT) in the carotid artery, which is a good surrogate marker for the systemic atherosclerosis, in a communitydwelling Japanese population.

\section{Methods}

\section{Subjects}

Inclusion criteria of participants of the present study were all individuals aged 35 or older who received health examinations conducted on Oki Island in 2015. Although we invited all the subjects according to the criteria, the participants in this study were mostly over 50 years of age due to a highly aging society in this area. The exclusion criterion was having severe disorders, such as advanced cancer, heart failure, frailty and renal failure with serum creatinine $(\mathrm{Cr})>2$ $\mathrm{mg} / \mathrm{dL}$. Participants were considered to have these diseases when they had already been diagnosed by medical doctors.

Based on these criteria, a total of 657 subjects (223 males and 434 females) were assigned to this study. Histories of smoking, hypertension, diabetes mellitus, and hypercholesterolemia were obtained through an interview. Blood pressure and fasting blood glucose measured on site were not included in the criteria for the diagnosis. This study was a part of the cohort study (Shimane CoHRE Study) conducted by the Center for the Community-based Health Research and Education, Shimane University. The Shimane CoHRE study started in 2006, and the population employed in this study was not the same as those in our previous reports performed for different aims ${ }^{23,24)}$.

\section{Ethics}

Written informed consent was obtained from each participant. The study protocol was approved by the local ethics committee of Shimane University.

\section{Data Collection}

Disease history, medication and information about lifestyle such as smoking, alcohol consumption and regular exercise were obtained by a questionnaire. Smokers were defined as subjects smoking daily (smokers: 1, and non-smokers: 2). Habitual drinkers were defined as subjects drinking alcohol regularly (habitual drinkers: 1, and non-habitual drinkers: 2). As for a habit of regular exercise, subjects self-reporting to have daily exercise were categorized as subjects having "regular exercise" (regular exercise: 1, and nonregular exercise: 2). It was recommended to include "ex-smoker" in the smoking status because smoking was shown to be a risk for atherosclerotic disorders even many years after quitting ${ }^{25}$. However, as our database included many missing data on previous smoking history, only the current smoking status was employed in the analysis.

Blood pressure was measured twice after taking a rest for at least $15 \mathrm{~min}$. The lower of the two measurements was taken as the blood pressure measured at site. Venous blood was collected after overnight fasting. A serum sample was separated and kept frozen at $-80^{\circ} \mathrm{C}$ until the measurement of HDL-C and the subclasses. Biochemical measurements of triglyceride (TG), low density lipoprotein cholesterol (LDL-C), and $\mathrm{Cr}$ were performed by standard enzymatic methods. Hemoglobin A1c (HbA1c) was determined by highperformance liquid chromatography (HPLC). Estimated glomerular filtration rate (eGFR) was calculated by the following formula revised by the working group of Japanese Chronic Kidney Disease Initiative $^{26)}$; eGFR $\left(\mathrm{mL} / \mathrm{min} / 1.73 \mathrm{~m}^{2}\right)=194 \times($ serum $\mathrm{Cr}$, $\mathrm{mg} / \mathrm{dL})^{-1.094} \times \mathrm{age}^{-0.287} \times(0.739$, if female $)$.

Intima-media thickness (IMT) in the carotid artery was measured with a high-resolution, real-time ultrasonography with a $7.5-\mathrm{MHz}$ transducer (Vivid I or LOGIQ e, GE, Tokyo, Japan). The measurement of the arterial wall thickness was performed at four segments in the bilateral carotid arteries; at $1.5-\mathrm{cm}$ distal to the bifurcation in the internal carotid artery (S1), at the bifurcation (S2), at $0-1.5 \mathrm{~cm}(\mathrm{~S} 3)$ and $1.5-3.0 \mathrm{~cm}(\mathrm{~S} 4)$ proximal to the bifurcation in the common carotid artery. The maximal value among the eight measurements at $S 1-4$ of the bilateral carotid arteries was analyzed as max-IMT in the present study. Eight measurements at $\mathrm{S} 1-4$ of the bilateral carotid arteries were summed up as plaque score (PS) if they were $1.1 \mathrm{~cm}$ or more.

\section{HDL2-C and HDL3-C Measurements}

The measurement of total HDL-C was per- 
HDL3-C

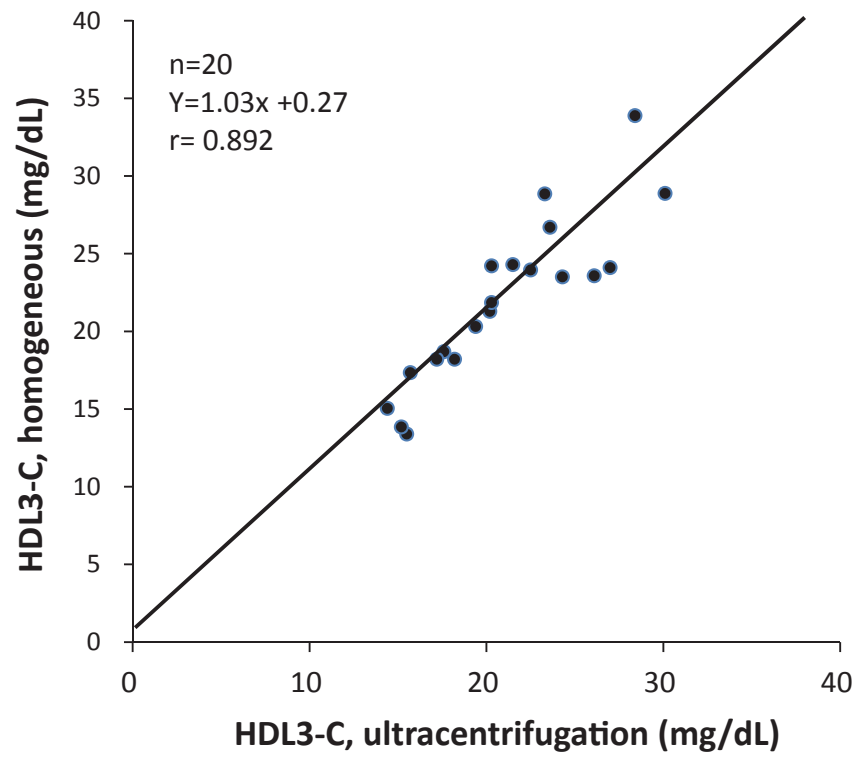

HDL2-C

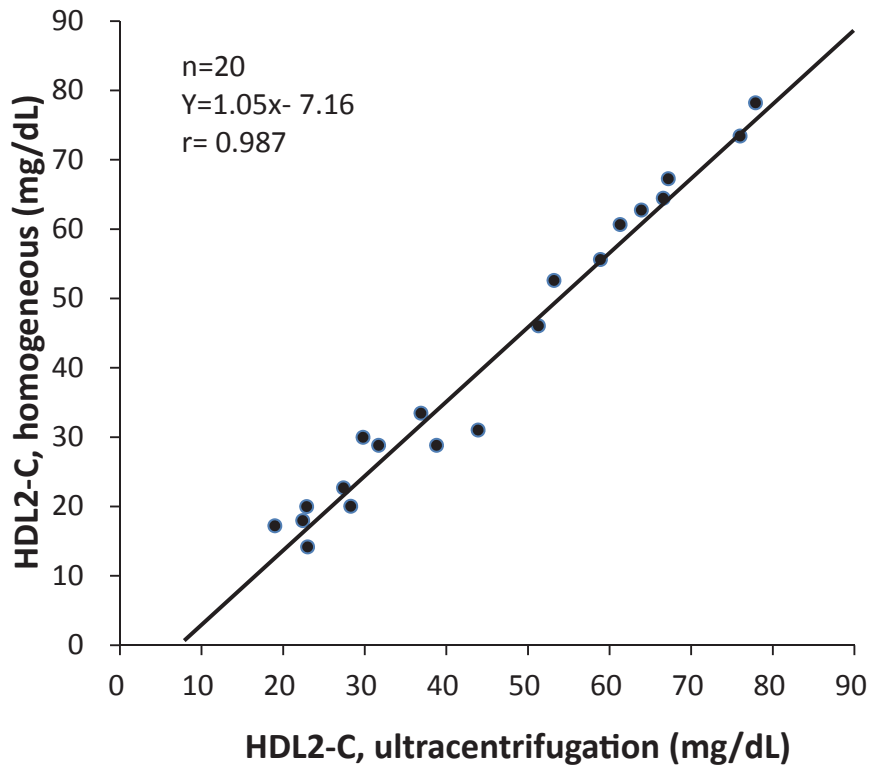

Fig. 1. Correlation between HDL-C subclasses determined by the homogeneous method and by ultracentrifugation.

formed using a commercial assay kit, MetaboLead ${ }^{\circledR}$ HDL-C (Kyowa Medex Co., Ltd. Tokyo, Japan) and a general auto-analyzer (JCA-BM6070, Nihon Denshi Co., Japan). The measurement of HDL3-C was performed using the homogeneous method developed by Kyowa Medex Co., Ltd. ${ }^{22)}$. In brief, not only LDL and VLDL but also HDL2 were coagulated in a solution with an adequate concentration of polyanions and magnesium because HDL2 has a higher positive charge compared with HDL3. Accordingly, HDL3-C reacted with cholesterol-related enzymes, such as cholesterol esterase and cholesterol oxidase, preferentially, and the HDL3-C level was quantified. The HDL2-C level was then determined by subtraction of HDL3-C from the total HDL-C level. The detection limit for total HDL-C and HDL3-C were 0.03 and $0.05 \mu \mathrm{mol} /$ $\mathrm{L}$, and the relative standard deviation $(\mathrm{SD})$ was $<4.7$ and $<2.9 \%$, respectively. The intra- and inter-assay coefficients of variations in the HDL3-C measurement were $1.9 \%$ and $2.1 \%$, respectively.

In order to validate the homogeneous method described above, the concentrations of the HDL subclasses measured by this method were compared with those by the ultracentrifugation method in 20 samples. Measurement by the ultracentrifugation was carried out in an outsourcing laboratory (SRL, Inc., Japan) according to the modified protocol of the methods reported previously. ${ }^{27,28)}$; a plasma sample was cooled on ice immediately and separated into two tubes with potassium bromide $(\mathrm{KBr})$. After adjustment for the density $(\mathrm{d}=1.063 \mathrm{~kg} / \mathrm{L}$ with $\mathrm{KBr}$ for
HDL-C, and $\mathrm{d}=1.125 \mathrm{~kg} / \mathrm{L}$ with $\mathrm{KBr}$ and sodium chloride $(\mathrm{NaCl})$ for HDL3-C), the sample was centrifuged at 223,000 $\times \mathrm{g}$ (L-60, Beckman-Coulter, Fullerton, CA) with Type 50.4 Ti Rotor (Beckman-Coulter) at $10^{\circ} \mathrm{C}$ for four $\mathrm{h}$. After aspiration of $40 \%$ of the supernatant (upper layer), the remaining sample was used for the measurement of cholesterol (Wako Pure Chemical Industries, Ltd.) to determine the concentration of the total HDL-C and the HDL3-C subfraction, respectively. The HDL2-C subfraction was determined by the following formula:

$$
\text { HDL2-C }=\left[(\text { HDL-C })-(\text { HDL3-C }) \times 1.54^{*}\right] \times 0.6^{* *}
$$

*; coefficients for dilution, and **; correction of the volume for aspiration

In addition, we determined the HDL3-C concentration using single precipitation methods to compare the homogeneous method developed by Kyowa Medex Co., Ltd. In the Warnick method, $50 \mu \mathrm{g}$ of HDL3 reagent $(19.1 \mathrm{~g} / \mathrm{L}$ Dextransulfate and $1.95 \mathrm{M}$ magnesium chloride $\left(\mathrm{MgCl}_{2}\right)$ ) was added to $0.5 \mathrm{~mL}$ serum. After vortex mixing, the mixture was placed at room temperature for $15 \mathrm{~min}$ and centrifuged at $12,000 \times \mathrm{g}$ for five min. Cholesterol concentrations of the supernatant in the isolated HDL3 were measured by the cholesterol assay. In the Hirano method, $60 \mu \mathrm{g}$ of HDL3 reagent $(12 \mathrm{~g} / \mathrm{L}$ Dextransulfate, $8.25 \mathrm{~g} / \mathrm{L}$ heparin and $98.7 \mathrm{~g} / \mathrm{L} \mathrm{MgCl}_{2}$ ) was added to $0.3 \mathrm{~mL}$ serum $^{29)}$. After vortex mixing, the mixture was placed to centrifuge at $10,000 \mathrm{rpm}$ for $10 \mathrm{~min}$. The supernatant was used for the measurement of HDL3-C. 
Table 1. Baseline characteristics of participants

\begin{tabular}{lccr}
\hline & Men & Women & $P$ \\
\hline $\mathrm{N}$ & 223 & 434 & 0.241 \\
Age, y & $72.1 \pm 7.9$ & $72.8 \pm 7.6$ & 0.074 \\
BMI, kg/m² & $23.5 \pm 2.9$ & $23.0 \pm 3.3$ & 0.002 \\
SBP, mmHg & $129.9 \pm 15.9$ & $134.1 \pm 16.3$ & 0.520 \\
DBP, mmHg & $75.8 \pm 9.5$ & $76.3 \pm 9.5$ & 0.508 \\
Hypertension, \% & 42.0 & 46.8 & $<0.001$ \\
Smoking, \% & 15.0 & 0.2 & 0.158 \\
Exercise, \% & 43.9 & 38.2 & $<0.001$ \\
Alcohol habits, \% & 62.1 & 15.2 & 0.021 \\
Diabetes, \% & 12.4 & 7.1 & $<0.001$ \\
Lipid lowering therapy, \% & 33.9 & $<0.001$ \\
LDL-C, mg/dL & 19.3 & $128.9 \pm 28.4$ & 0.036 \\
HDL-C, mg/dL & $114.4 \pm 27.2$ & $61.2 \pm 14.6$ & 0.087 \\
HDL2-C, mg/dL & $58.6 \pm 15.9$ & $40.3 \pm 14.7$ & 0.100 \\
HDL3-C, mg/dL & $38.2 \pm 15.2$ & $20.9 \pm 3.6$ & 0.640 \\
TG, mg/dL & $20.4 \pm 3.8$ & $95.5[91.2,97.7]$ & 0.329 \\
HbAlc (NGSP), \% & $93.3[87.1,97.7]$ & $5.84 \pm 0.42$ & 0.835 \\
eGFR, mL/min/1.73 m ${ }^{2}$ & $5.87 \pm 0.56$ & $69.4 \pm 15.1$ & $<0.001$ \\
max-IMT, mm & $69.2 \pm 16.4$ & $1.65[1.59,1.71]$ & $<0.001$ \\
Plaque score & $1.99[1.87,2.12]$ & $3.95[3.85,4.06]$ & \\
\hline
\end{tabular}

Data was expressed as the mean \pm SD or the mean [95\% confident interval].

Statistical significance was examined either by Student's $t$-test or $\chi^{2}$-test.

\section{Statistics}

Data were expressed as mean \pm SD. Because of a skewed distribution, the serum TG level and maxIMT were analyzed after logarithmic (log) transformation. Pearson's correlation coefficient and analysis of variance (ANOVA) were employed in univariate analyses between max-IMT and other variables. Then, the multiple linear regression and the multiple logistic regression analyses were performed to examine an association of max-IMT with the HDL subclasses. In the logistic regression analysis, subjects were divided into two groups according to their max-IMT following a clinical criterion $^{30-32)}$; subjects with max-IMT $\geq 1.5$ $\mathrm{mm}$ were categorized as "atherosclerotic". As for PS, those over the median $(>4.0)$ were categorized as "atherosclerotic". All statistical analyses were performed with the use of the IBM SPSS Statistic software (SPSS Statistics 21). Statistical significance was defined as $p<$ 0.05 .

\section{Results}

\section{Validation of the Homogenous Method to Quantify the HDL-C Subclasses}

In order to validate the new measurement method, levels of HDL-C subclasses determined by the homogenous method were compared with those by ultracentrifugation. As shown in Fig. 1, a strong correlation was obtained between the two methods $[r=0.89, p<0.001$ for HDL3-C and $r=0.99, p<$ 0.001 for HDL2-C], indicating that the homogenous method was reliable as a quantification method of the HDL subclasses, at least in the ranges shown in Fig. 1. In addition, in terms of HDL3-C, the correlation of the homogenous method with the ultracentrifugation method was significantly better than the Warnick method and at least comparable to the Hirano method (Supplementary Fig. 1).

\section{Demographic Data of the Studied Population}

The baseline characteristics of the 657 participants (223 men and 434 women) were shown in Table 1. LDL-C, HDL-C and HDL2-C were significantly higher in women than in men, though subjects taking anti-hyperlipidemic drugs were found more in women. HDL3-C tended to be higher in women than in men, though it did not reach a significant level. Max-IMT and the ratio of smokers and diabetes mellitus were significantly higher in men than in women.

\section{Impact of the Level of HDL-C Subclasses on Max- IMT and PS}

A simple regression analysis showed that maxIMT and PS showed an inverse correlation with 
Table 2A. Simple regression analysis for max-IMT

\begin{tabular}{|c|c|c|c|c|c|c|}
\hline \multirow[b]{2}{*}{ variables } & \multicolumn{2}{|c|}{ All } & \multicolumn{2}{|c|}{ Men } & \multicolumn{2}{|c|}{ Women } \\
\hline & $r$ & $p$ & r & $p$ & $r$ & $p$ \\
\hline Age & 0.341 & $<0.0001$ & 0.363 & $<0.0001$ & 0.359 & $<0.0001$ \\
\hline BMI & -0.084 & 0.032 & -0.252 & 0.0002 & -0.023 & 0.638 \\
\hline SBP & 0.029 & 0.466 & -0.079 & 0.241 & 0.137 & 0.004 \\
\hline DBP & -0.145 & 0.0002 & -0.256 & 0.0001 & -0.075 & 0.120 \\
\hline LDL-C & -0.099 & 0.011 & -0.038 & 0.570 & -0.060 & 0.210 \\
\hline HDL-C & -0.069 & 0.077 & -0.016 & 0.815 & -0.078 & 0.105 \\
\hline HDL2-C & -0.032 & 0.412 & 0.021 & 0.758 & -0.043 & 0.376 \\
\hline HDL3-C & -0.153 & $<0.0001$ & -0.150 & 0.026 & -0.140 & 0.004 \\
\hline $\log T G$ & 0.03 & 0.449 & -0.035 & 0.603 & 0.085 & 0.078 \\
\hline HbA1c (NGSP) & 0.111 & 0.004 & 0.038 & 0.574 & 0.162 & 0.0008 \\
\hline eGFR & -0.111 & 0.005 & 0.036 & 0.593 & -0.163 & 0.0007 \\
\hline
\end{tabular}

Pearson's correlation coefficient $(\mathrm{r})$ is shown with $p$ value.

Table 2B. Simple regression analysis for Plaque score

\begin{tabular}{|c|c|c|c|c|c|c|}
\hline \multirow[b]{2}{*}{ variables } & \multicolumn{2}{|c|}{ All } & \multicolumn{2}{|c|}{ Men } & \multicolumn{2}{|c|}{ Women } \\
\hline & $r$ & $p$ & $r$ & $p$ & $r$ & $p$ \\
\hline Age & 0.368 & $<0.0001$ & 0.408 & $<0.0001$ & 0.384 & $<0.0001$ \\
\hline BMI & -0.073 & 0.064 & -0.220 & $<0.001$ & -0.023 & 0.639 \\
\hline SBP & 0.016 & 0.679 & -0.090 & 0.181 & 0.135 & 0.005 \\
\hline DBP & -0.142 & $<0.001$ & -0.263 & $<0.0001$ & -0.064 & 0.186 \\
\hline LDL-C & -0.122 & 0.002 & -0.096 & 0.156 & -0.053 & 0.275 \\
\hline HDL-C & -0.124 & 0.002 & -0.095 & 0.158 & -0.117 & 0.015 \\
\hline HDL2-C & -0.078 & 0.046 & -0.043 & 0.526 & -0.078 & 0.107 \\
\hline HDL3-C & -0.191 & $<0.0001$ & -0.226 & $<0.001$ & -0.154 & 0.001 \\
\hline $\log T G$ & 0.009 & 0.814 & -0.097 & 0.151 & 0.099 & 0.039 \\
\hline HbA1c (NGSP) & 0.128 & 0.001 & 0.107 & 0.113 & 0.137 & 0.005 \\
\hline eGFR & -0.163 & $<0.0001$ & -0.138 & 0.041 & -0.186 & 0.0001 \\
\hline Max-IMT & 0.771 & $<0.0001$ & 0.781 & $<0.0001$ & 0.742 & $<0.0001$ \\
\hline
\end{tabular}

Pearson's correlation coefficient $(\mathrm{r})$ is shown with $p$ value.

HDL3-C but not with HDL2-C (Table 2A and 2B). This correlation was still observed when the analysis was done in men and women separately. HDL-C showed an inverse correlation with max-IMT and PS as well, which was, however, weaker when compared with HDL3-C. HDL3-C showed a modest inverse association with age in men as well as in women whereas HDL2-C did not (Table 3). Interestingly, HDL3-C was not associated with HDL2-C, although HDL3-C was significantly associated with DBP, LDL$\mathrm{C}$, and HDL-C (Table 3).

In spite of the significant correlation found in the simple regression, multiple linear regression analysis under adjustment of confounding factors indicated that HDL3-C was not associated with max-IMT as well as PS (Table 4A and 4B). Age, male gender, and smoking in the younger population and male gender, $\mathrm{HbA1c}$, and lower BMI in the elderly population were factors positively associated with max-IMT (Table 4A). In addition, multiple logistic regression analysis showed that in both the younger and elder population, HDL3-C was not selected as an independent factor to identify "atherosclerotic" subjects with maxIMT $\geq 1.5 \mathrm{~mm}$ under adjustment with covariates (Table 5A). These findings were consistent with those on PS (Table 4B and 5B), suggesting that the apparent association between HDL3-C and max-IMT as well as PS in a simple regression analysis was mainly due to a strong confounder, i.e., age. 
Table 3. Simple regression analysis for HDL2-C and HDL3-C

\begin{tabular}{|c|c|c|c|c|c|c|c|c|}
\hline & \multicolumn{4}{|c|}{ HDL3-C } & \multicolumn{4}{|c|}{ HDL2-C } \\
\hline & \multicolumn{2}{|c|}{ Men } & \multicolumn{2}{|c|}{ Women } & \multicolumn{2}{|c|}{ Men } & \multicolumn{2}{|c|}{ Women } \\
\hline & $r$ & $p$ & $r$ & $p$ & $r$ & $p$ & $r$ & $p$ \\
\hline Age & -0.322 & $<0.0001$ & -0.315 & $<0.0001$ & -0.006 & 0.935 & -0.078 & 0.103 \\
\hline BMI & 0.084 & 0.213 & 0.193 & $<0.0001$ & -0.275 & $<0.0001$ & -0.282 & $<0.0001$ \\
\hline SBP & 0.096 & 0.152 & 0.078 & 0.103 & 0.073 & 0.279 & -0.064 & 0.186 \\
\hline DBP & 0.315 & $<0.0001$ & 0.200 & $<0.0001$ & 0.131 & 0.051 & -0.074 & 0.125 \\
\hline LDL-C & 0.312 & $<0.0001$ & 0.296 & $<0.0001$ & -0.133 & 0.047 & -0.071 & 0.139 \\
\hline HDL-C & 0.262 & $<0.0001$ & 0.155 & 0.0012 & 0.965 & $<0.0001$ & 0.968 & $<0.0001$ \\
\hline HDL2-C & 0.038 & 0.573 & -0.062 & 0.194 & & & & \\
\hline HDL3-C & & & & & 0.038 & 0.573 & -0.062 & 0.194 \\
\hline TG & -0.019 & 0.781 & 0.017 & 0.726 & -0.547 & $<0.0001$ & -0.521 & $<0.0001$ \\
\hline HbAlc (NGSP) & 0.073 & 0.277 & 0.082 & 0.087 & -0.048 & 0.476 & -0.143 & 0.003 \\
\hline
\end{tabular}

Pearson's correlation coefficient $(r)$ is shown with $p$ value.

\section{Effects of Medication}

Since medication, such as statins and fibrates, has not been considered in the analysis above, we further assessed the relationship between HDL3-C and maxIMT in subjects without lipid-lowering medication $(n=465)$. Multiple linear regression analysis indicated that HDL3-C was not associated with max-IMT (Table 6A), although HDL3-C significantly and inversely correlated with max-IMT in a simple regression analysis (data not shown). These findings were consistent with the results of multiple logistic regression analysis (Table 6B).

\section{Discussion}

We found that serum concentration of HDL-C subclasses measured by the homogenous assay was well correlated with that measured by ultracentrifugation, and that not HDL2-C but HDL3-C was inversely associated with age. Although HDL3-C was inversely correlated with max-IMT as well as PS in a simple regression, the significant correlation was not observed under adjustment with confounding factors including age. These findings suggested that serum level of HDL-C subclasses was not independently associated with carotid IMT in this population.

Although HDL-C has been considered to be protective against atherosclerosis and cardiovascular events, recent evidence does not support this idea ${ }^{10,33-35)}$. In this context, HDL2 and HDL3 have attracted much attention as they may possess key roles to explain the discrepancy of the role of HDL. In fact, previous studies showed that the HDL3-C level was inversely associated with coronary and peripheral arterial diseases, plaque formation or plaque area, and cardiovascular events and mortality $\left.{ }^{13}, 16,36-41\right)$. However, as findings inconsistent with those above have been reported as well ${ }^{42-46)}$, pathophysiological roles of the HDL subclasses have not been confirmed yet. Concerning the relationship between HDL subclasses and atherosclerosis, some investigators have reported that the HDL2-C level is inversely associated with carotid artery wall thickness ${ }^{42,45)}$, while the HDL3-C level has been reported to be inversely associated with carotid plaque area ${ }^{13)}$ and with plaques in the femoral sites ${ }^{36)}$. Taken together, the role of HDL-C subclasses in plaque formation and prevention against cardiovascular events are still controversial. On the other hand, according to recent studies regarding total HDL-C level, it was inversely associated with carotid IMT especially in middle-aged men ${ }^{47)}$ and was protective against coronary heart disease unless it was not very high ${ }^{48)}$.

In the present study, the serum HDL2-C level was higher than the HDL3-C level, which was consistent with previous reports in Japanese populations ${ }^{21,49)}$. In contrast, in Caucasians and Hispanics, the HDL3C level was higher than the HDL2-C level ${ }^{13}, 14,16,45,50$ ). Dietary factors may affect the HDL-C subclass level. In this context, we should keep in mind that fish is a common food in Japan especially in the Oki Islands. Previous studies suggested that the serum HDL2-C level was influenced by dietary intake of saturated fatty acids ${ }^{50,51)}$. However, a twin study indicated that effects of long-term dietary habits on the serum lipid levels were determined largely by the genetic factor ${ }^{52)}$. In addition, because polymorphisms of the hepatic lipase and the cholesteryl ester transfer protein genes can affect the serum level of HDL-C and of the subclasses ${ }^{53}{ }^{54)}$, the discrepancy between Japanese/Asians and Caucasians/Hispanics in terms of the serum level 
Table 4A. Multiple linear regression analysis for max-IMT

\begin{tabular}{|c|c|c|c|c|c|c|c|c|}
\hline \multirow[b]{2}{*}{ variables } & \multicolumn{4}{|c|}{$\leqq 73$ years-old $(n=346)$} & \multicolumn{4}{|c|}{$>73$ years-old $(n=311)$} \\
\hline & beta & SE & std beta & $p$ & beta & SE & std beta & $p$ \\
\hline Age & 0.009 & 0.002 & 0.271 & $<0.0001$ & 0.002 & 0.003 & 0.041 & 0.501 \\
\hline Gender* & -0.066 & 0.023 & -0.185 & 0.004 & -0.089 & 0.028 & -0.230 & 0.001 \\
\hline HDL3-C & 0.002 & 0.003 & 0.045 & 0.415 & -0.004 & 0.003 & -0.082 & 0.194 \\
\hline HDL2-C & 0.005 & 0.001 & 0.047 & 0.465 & -0.0002 & 0.001 & -0.018 & 0.796 \\
\hline LDL-C & 0.0001 & 0.0003 & 0.019 & 0.739 & 0.0001 & 0.001 & 0.0001 & 0.999 \\
\hline LogTG & 0.092 & 0.049 & 0.111 & 0.067 & 0.024 & 0.071 & 0.023 & 0.739 \\
\hline BMI & -0.002 & 0.003 & -0.039 & 0.487 & -0.007 & 0.004 & -0.122 & 0.046 \\
\hline DBP & -0.0001 & 0.001 & -0.007 & 0.895 & -0.002 & 0.001 & -0.098 & 0.103 \\
\hline HbA1c (NGSP) & 0.016 & 0.019 & 0.046 & 0.384 & 0.050 & 0.022 & 0.129 & 0.027 \\
\hline eGFR & 0.001 & 0.001 & 0.092 & 0.086 & 0.0002 & 0.001 & 0.015 & 0.802 \\
\hline Alcohol habits & 0.003 & 0.021 & 0.008 & 0.895 & 0.002 & 0.029 & 0.004 & 0.958 \\
\hline Smoking & -0.094 & 0.035 & -0.156 & 0.007 & 0.030 & 0.075 & 0.023 & 0.689 \\
\hline Exercise & -0.019 & 0.018 & -0.054 & 0.301 & $<0.0001$ & 0.021 & -0.0001 & 0.999 \\
\hline
\end{tabular}

SE: standard error of beta, std beta: standardized beta, ${ }^{*} 1$ : men, 2 : women

Table 4B. Multiple linear regression analysis for Plaque score

\begin{tabular}{|c|c|c|c|c|c|c|c|c|}
\hline \multirow[b]{2}{*}{ variables } & \multicolumn{4}{|c|}{$\leqq 73$ years-old $(n=346)$} & \multicolumn{4}{|c|}{$>73$ years-old $(n=311)$} \\
\hline & beta & SE & std beta & $p$ & beta & SE & std beta & $p$ \\
\hline Age & 0.008 & 0.001 & 0.315 & $<0.0001$ & 0.002 & 0.002 & 0.050 & 0.400 \\
\hline Gender* & -0.044 & 0.015 & -0.182 & 0.004 & -0.081 & 0.020 & -0.281 & 0.0001 \\
\hline HDL3-C & -0.001 & 0.002 & -0.017 & 0.757 & -0.004 & 0.002 & -0.113 & 0.066 \\
\hline HDL2-C & -0.0004 & 0.001 & -0.057 & 0.361 & -0.0004 & 0.001 & -0.047 & 0.497 \\
\hline LDL-C & 0.0001 & 0.0002 & 0.016 & 0.777 & -0.0001 & 0.0001 & -0.025 & 0.667 \\
\hline LogTG & -0.003 & 0.03 & -0.005 & 0.933 & 0.015 & 0.051 & 0.020 & 0.767 \\
\hline BMI & -0.001 & 0.002 & -0.017 & 0.769 & -0.006 & 0.003 & -0.138 & 0.019 \\
\hline DBP & 0.0002 & 0.001 & 0.019 & 0.718 & -0.001 & 0.001 & -0.092 & 0.112 \\
\hline HbA1c (NGSP) & 0.021 & 0.013 & 0.087 & 0.093 & 0.036 & 0.016 & 0.127 & 0.024 \\
\hline eGFR & 0.0001 & 0.0004 & 0.009 & 0.852 & -0.0001 & 0.001 & -0.012 & 0.830 \\
\hline Alcohol habits & 0.005 & 0.014 & 0.022 & 0.703 & 0.006 & 0.021 & 0.020 & 0.774 \\
\hline Smoking & -0.052 & 0.023 & -0.126 & 0.027 & 0.009 & 0.054 & 0.009 & 0.870 \\
\hline Exercise & -0.003 & 0.012 & -0.014 & 0.792 & 0.021 & 0.015 & 0.078 & 0.165 \\
\hline
\end{tabular}

SE: standard error of beta, std beta: standardized beta, ${ }^{*} 1$ : men, 2 : women

of the HDL-C subclasses may be explained by the different genetic background among the population studied. Furthermore, a recent study indicated that efflux capacity of HDL-C was also different between Asians and Caucasians, which might be explained by the difference in the ratio between HDL3 and HDL2 ${ }^{55)}$.

This is the first report showing a significant correlation between age and HDL3-C. It is of note that HDL2-C showed no correlation with age at all (Table 3). This observation seemed reliable because we obtained consistent results both in men and women. The correlation between HDL3-C and age may be related to sedentary life style in an aged population. Although, to the best of our knowledge, disease prevalence on the Oki Islands was not largely deviated from the average of Japanese populations, future study is needed to evaluate the association between disease prevalence and the HDL3-C level. Further, this observation is not consistent with those of previous reports showing that not HDL3-C but HDL2-C positively correlated with age in Caucasian/Hispanic populations ${ }^{56,57)}$. This discrepancy between Japanese and Caucasians/Hispanics is again enigmatic. Further studies on precise metabolisms of the HDL-C sub- 
Table 5A. Multiple logistic regression analysis for max-IMT

\begin{tabular}{|c|c|c|c|c|c|c|c|c|}
\hline \multirow{3}{*}{$\begin{array}{l}\text { variables } \\
\text { Age }\end{array}$} & \multicolumn{4}{|c|}{$\leqq 73$ years-old $(n=346)$} & \multicolumn{4}{|c|}{$>73$ years-old $(n=311)$} \\
\hline & \multirow{2}{*}{$\frac{\mathrm{OR}}{1.143}$} & \multicolumn{2}{|c|}{$95 \% \mathrm{CI}$} & \multirow{2}{*}{$\frac{p}{<0.0001}$} & \multirow{2}{*}{$\frac{\mathrm{OR}}{1.058}$} & \multicolumn{2}{|c|}{$95 \% \mathrm{CI}$} & \multirow{2}{*}{$\frac{p}{0.143}$} \\
\hline & & 1.077 & 1.213 & & & 0.981 & 1.142 & \\
\hline Gender* & 0.436 & 0.238 & 0.796 & 0.007 & 0.408 & 0.196 & 0.849 & 0.016 \\
\hline HDL3-C & 0.989 & 0.924 & 1.059 & 0.749 & 0.968 & 0.891 & 1.052 & 0.444 \\
\hline HDL2-C & 0.996 & 0.977 & 1.016 & 0.702 & 1.012 & 0.990 & 1.035 & 0.277 \\
\hline LDL-C & 1.005 & 0.997 & 1.014 & 0.233 & 1.002 & 0.993 & 1.012 & 0.628 \\
\hline $\log T G$ & 1.899 & 0.502 & 7.181 & 0.345 & 4.157 & 0.682 & 25.33 & 0.122 \\
\hline BMI & 0.980 & 0.904 & 1.064 & 0.633 & 0.964 & 0.882 & 1.055 & 0.428 \\
\hline DBP & 1.002 & 0.976 & 1.028 & 0.892 & 0.993 & 0.965 & 1.022 & 0.638 \\
\hline HbA1c (NGSP) & 1.275 & 0.779 & 2.086 & 0.334 & 1.702 & 0.941 & 3.080 & 0.079 \\
\hline eGFR & 1.020 & 1.003 & 1.038 & 0.020 & 1.014 & 0.994 & 1.034 & 0.185 \\
\hline Alcohol habits & 0.672 & 0.379 & 1.191 & 0.173 & 0.713 & 0.337 & 1.051 & 0.377 \\
\hline Smoking & 0.297 & 0.108 & 0.815 & 0.018 & 0.808 & 0.084 & 7.811 & 0.854 \\
\hline Exercise & 0.875 & 0.541 & 1.415 & 0.585 & 1.155 & 0.678 & 1.968 & 0.596 \\
\hline
\end{tabular}

A dichotomous variable according to max-IMT (i.e., max-IMT $\geqq 1.5 \mathrm{~mm}$ vs. $<1.5 \mathrm{~mm}$ ) was examined in the analysis.

OR: odds ratio, $95 \% \mathrm{CI}$ : $95 \%$ confidence interval, ${ }^{*} 1$ : men, 2 : women

Table 5B. Multiple logistic regression analysis for Plaque score

\begin{tabular}{|c|c|c|c|c|c|c|c|c|}
\hline \multirow{3}{*}{$\frac{\text { variables }}{\text { Age }}$} & \multicolumn{4}{|c|}{$\leqq 73$ years-old $(n=346)$} & \multicolumn{4}{|c|}{$>73$ years-old $(n=311)$} \\
\hline & \multirow{2}{*}{$\frac{\mathrm{OR}}{1.125}$} & \multicolumn{2}{|c|}{$95 \% \mathrm{CI}$} & \multirow{2}{*}{$\frac{p}{0.0002}$} & \multirow{2}{*}{$\frac{\mathrm{OR}}{1.049}$} & \multicolumn{2}{|c|}{$95 \% \mathrm{CI}$} & \multirow{2}{*}{$\frac{p}{0.170}$} \\
\hline & & 1.058 & 1.197 & & & 0.980 & 1.124 & \\
\hline Gender* & 0.495 & 0.271 & 0.906 & 0.023 & 0.410 & 0.209 & 0.803 & 0.009 \\
\hline HDL3-C & 0.986 & 0.918 & 1.059 & 0.706 & 0.949 & 0.876 & 1.027 & 0.194 \\
\hline HDL2-C & 0.987 & 0.967 & 1.007 & 0.193 & 1.001 & 0.981 & 1.022 & 0.900 \\
\hline LDL-C & 1.001 & 0.992 & 1.010 & 0.899 & 0.996 & 0.987 & 1.005 & 0.361 \\
\hline $\log T G$ & 1.809 & 0.464 & 7.050 & 0.393 & 0.994 & 0.191 & 5.182 & 0.995 \\
\hline BMI & 0.983 & 0.904 & 1.070 & 0.697 & 0.960 & 0.883 & 1.044 & 0.340 \\
\hline DBP & 1.000 & 0.973 & 1.026 & 0.972 & 0.998 & 0.972 & 1.025 & 0.903 \\
\hline HbA1c (NGSP) & 1.723 & 1.028 & 2.887 & 0.039 & 1.260 & 0.735 & 2.160 & 0.400 \\
\hline eGFR & 1.007 & 0.990 & 1.025 & 0.394 & 1.001 & 0.983 & 1.019 & 0.908 \\
\hline Alcohol habits & 1.248 & 0.702 & 2.220 & 0.450 & 0.888 & 0.440 & 1.789 & 0.739 \\
\hline Smoking & 0.694 & 0.278 & 1.735 & 0.435 & 0.499 & 0.052 & 4.739 & 0.545 \\
\hline Exercise & 1.190 & 0.726 & 1.951 & 0.490 & 1.192 & 0.724 & 1.960 & 0.490 \\
\hline
\end{tabular}

A dichotomous variable according to plaque score (i.e., plaque score $>4.0$ vs. $\leqq 4.0$ ) was examined in the analysis.

OR: odds ratio, $95 \% \mathrm{CI}$ : $95 \%$ confidence interval, ${ }^{*} 1$ : men, 2 : women

classes are essential to solve these questions. In addition, as our population was rather aged (mean age was 73 years); it may be necessary to examine the levels of the HDL-C subclasses in a younger generation.

Although the present study could not show a significant association of HDL2 or HDL3 with maxIMT, this observation did not negate pathophysiological significance of HDL3 in atherosclerosis; as age is a strong confounder, it may be necessary to design studies to dissociate effects of HDL3 from those of age.
Furthermore, we did not consider the presence of exsmokers in the analysis, which could be a limitation of our study. It might affect the association of HDL subfractions with carotid atherosclerosis, because it is well known that smoking decreases HDL-C whereas cessation of smoking increases HDL-C. In addition, roles of HDL subclasses in the cholesterol metabolism may need to be clarified in experimental studies. Recent studies demonstrated that the cholesterol efflux capacity of macrophages was inversely associated with 
Table 6A. Multiple linear regression analysis for max-IMT in 453 subjects without lipid lowering therapy

\begin{tabular}{lcccc}
\hline & \multicolumn{4}{c}{ Without lipid lowering therapy $(n=453)$} \\
\cline { 2 - 4 } variables & beta & SE & std beta & $p$ \\
\hline Age & 0.009 & 0.001 & 0.359 & $<0.00001$ \\
Gender & -0.095 & 0.020 & -0.249 & $<0.00001$ \\
HDL3-C & -0.002 & 0.003 & -0.033 & 0.523 \\
HDL2-C & 0.0004 & 0.0006 & 0.031 & 0.551 \\
LDL-C & 0.0003 & 0.0003 & 0.044 & 0.376 \\
LogTG & 0.052 & 0.047 & 0.057 & 0.268 \\
BMI & -0.004 & 0.003 & -0.059 & 0.196 \\
DBP & -0.001 & 0.001 & -0.041 & 0.366 \\
HbA1c (NGSP) & 0.024 & 0.018 & 0.057 & 0.190 \\
eGFR & 0.001 & 0.0006 & 0.072 & 0.129 \\
Alcohol habits & -0.007 & 0.019 & -0.019 & 0.713 \\
Smoking & -0.079 & 0.034 & -0.109 & 0.020 \\
Exercise & -0.014 & 0.016 & -0.038 & 0.383 \\
\hline
\end{tabular}

SE: standard error of beta, std beta: standardized beta, ${ }^{*} 1$ : men, 2 : women

Table 6B. Multiple logistic regression analysis for max-IMT in 453 subjects without lipid lowering therapy

\begin{tabular}{lcccc}
\hline & \multicolumn{4}{c}{ Without lipid lowering therapy $(n=453)$} \\
\cline { 2 - 4 } variables & OR & $95 \%$ CI & $p$ \\
\hline Age & 1.127 & 1.087 & 1.168 & $<0.0001$ \\
Gender & 0.341 & 0.200 & 0.583 & 0.0001 \\
HDL3-C & 0.950 & 0.890 & 1.015 & 0.129 \\
HDL2-C & 1.008 & 0.992 & 1.025 & 0.338 \\
LDL-C & 1.010 & 1.002 & 1.018 & 0.016 \\
LogTG & 1.790 & 0.535 & 5.994 & 0.345 \\
BMI & 1.010 & 0.940 & 1.085 & 0.780 \\
DBP & 1.002 & 0.980 & 1.024 & 0.890 \\
HbA1c (NGSP) & 1.364 & 0.855 & 2.177 & 0.193 \\
eGFR & 1.018 & 1.003 & 1.034 & 0.018 \\
Alcohol habits & 0.604 & 0.357 & 1.021 & 0.060 \\
Smoking & 0.244 & 0.090 & 0.664 & 0.006 \\
Exercise & 1.037 & 0.680 & 1.581 & 0.867 \\
\hline A dichotomous variable according to max-IMT (i.e., & max-IMT $\geqq 1.5 \mathrm{~mm}$ vs. $<1.5 \mathrm{~mm}$ was \\
examined in the analysis. & & &
\end{tabular}

carotid IMT, with the risk of angiographic coronary artery disease and with the incident of coronary heart disease, independently of HDL-C levels ${ }^{58-60)}$. It is of interest to examine a correlation between cholesterol efflux capacity and the ratio HDL3-C/HDL2-C in a future study.

In conclusion, we found that the serum level of HDL3-C was inversely associated with age, and that the HDL-C subclass was not independently associated with max-IMT and PS in a general Japanese population. Direct measurement of HDL-C subclasses by the homogenous assay is a simple and reliable method, which can be applied in epidemiological and clinical studies.

\section{Acknowledgments}

Authors appreciate Dr. Kenji Karino, Ms. Nobuko 
Tanaka, Mr. Ryota Okazaki, Ms. Satoko Mishima, and all the CoHRE study members for their skillful assistance.

Authors also appreciate the generous cooperation and technical support of Kyowa Medex, Co., Ltd.

\section{Conflict of Interest Statement}

All authors have no conflicts of interest.

\section{References}

1) M.J. Stampfer, F.M. Sacks, S. Salvini, W.C. Willett, C.H. Hennekens, A prospective study of cholesterol, apolipoproteins, and the risk of myocardial infarction, $\mathrm{N}$ Engl J Med. 1991; 325: 373-381

2) P.M. Sweetnam, C.H. Bolton, J.W. Yarnell, D. Bainton, I.A. Baker, P.C. Elwood, N.E. Miller, Associations of the HDL2 and HDL3 cholesterol subfractions with the development of ischemic heart disease in British men. The Caerphilly and Speedwell Collaborative Heart Disease Studies, Circulation. 1994; 90: 769-774

3) T. Gordon, W.P. Castelli, M.C. Hjortland, W.B. Kannel, T.R. Dawber, High density lipoprotein as a protective factor against coronary heart disease. The Framingham Study, Am J Med. 1997; 62: 707-714

4) D.J. Maron, The epidemiology of low levels of high-density lipoprotein cholesterol in patients with and without coronary artery disease, Am J Cardiol. 2000; 86: 11L-14L

5) R.L. Sacco, R.T. Benson, D.E. Kargman, B. BodenAlbala, C. Tuck, I.F. Lin, J.F. Cheng, M.C. Paik, S. Shea, L. Berglund, High-density lipoprotein cholesterol and ischemic stroke in the elderly: the Northern Manhattan Stroke Study, JAMA. 2001; 285: 2729-2735

6) C. Baigent, A. Keech, P.M. Kearney, L. Blackwell, G. Buck, C. Pollicino, A. Kirby, T. Sourjina, R. Peto, R. Collins, R. Simes, C. Cholesterol Treatment Trialists, Efficacy and safety of cholesterol-lowering treatment: prospective meta-analysis of data from 90,056 participants in 14 randomised trials of statins, Lancet. 2005; 366: 1267-1278

7) C. Emerging Risk Factors, E. Di Angelantonio, N. Sarwar, P. Perry, S. Kaptoge, K.K. Ray, A. Thompson, A.M. Wood, S. Lewington, N. Sattar, C.J. Packard, R. Collins, S.G. Thompson, J. Danesh, Major lipids, apolipoproteins, and risk of vascular disease, JAMA. 2009; 302: 1993-2000

8) L. Zhang, Q. Qiao, J. Tuomilehto, N. Hammar, G. Ruotolo, C.D. Stehouwer, R.J. Heine, M. Eliasson, B. Zethelius, D.S. Group, The impact of dyslipidaemia on cardiovascular mortality in individuals without a prior history of diabetes in the DECODE Study, Atherosclerosis. 2009; 206: 298-302

9) M. Briel, I. Ferreira-Gonzalez, J.J. You, P.J. Karanicolas, E.A. Akl, P. Wu, B. Blechacz, D. Bassler, X. Wei, A. Sharman, I. Whitt, S. Alves da Silva, Z. Khalid, A.J. Nordmann, Q. Zhou, S.D. Walter, N. Vale, N. Bhatnagar, C. O'Regan, E.J. Mills, H.C. Bucher, V.M. Montori, G.H. Guyatt, Association between change in high density lipoprotein cholesterol and cardiovascular disease morbidity and mortality: systematic review and meta-regression analysis, BMJ. 2009; 338: b92

10) B.F. Voight, G.M. Peloso, M. Orho-Melander, R. FrikkeSchmidt, M. Barbalic, M.K. Jensen, G. Hindy, H. Holm, E.L. Ding, T. Johnson, H. Schunkert, N.J. Samani, R. Clarke, J.C. Hopewell, J.F. Thompson, M. Li, G. Thorleifsson, C. Newton-Cheh, K. Musunuru, J.P. Pirruccello, D. Saleheen, L. Chen, A. Stewart, A. Schillert, U. Thorsteinsdottir, G. Thorgeirsson, S. Anand, J.C. Engert, T. Morgan, J. Spertus, M. Stoll, K. Berger, N. Martinelli, D. Girelli, P.P. McKeown, C.C. Patterson, S.E. Epstein, J. Devaney, M.S. Burnett, V. Mooser, S. Ripatti, I. Surakka, M.S. Nieminen, J. Sinisalo, M.L. Lokki, M. Perola, A. Havulinna, U. de Faire, B. Gigante, E. Ingelsson, T. Zeller, P. Wild, P.I. de Bakker, O.H. Klungel, A.H. Maitland-van der Zee, B.J. Peters, A. de Boer, D.E. Grobbee, P.W. Kamphuisen, V.H. Deneer, C.C. Elbers, N.C. Onland-Moret, M.H. Hofker, C. Wijmenga, W.M. Verschuren, J.M. Boer, Y.T. van der Schouw, A. Rasheed, P. Frossard, S. Demissie, C. Willer, R. Do, J.M. Ordovas, G.R. Abecasis, M. Boehnke, K.L. Mohlke, M.J. Daly, C. Guiducci, N.P. Burtt, A. Surti, E. Gonzalez, S. Purcell, S. Gabriel, J. Marrugat, J. Peden, J. Erdmann, P. Diemert, C. Willenborg, I.R. Konig, M. Fischer, C. Hengstenberg, A. Ziegler, I. Buysschaert, D. Lambrechts, F. Van de Werf, K.A. Fox, N.E. El Mokhtari, D. Rubin, J. Schrezenmeir, S. Schreiber, A. Schafer, J. Danesh, S. Blankenberg, R. Roberts, R. McPherson, H. Watkins, A.S. Hall, K. Overvad, E. Rimm, E. Boerwinkle, A. Tybjaerg-Hansen, L.A. Cupples, M.P. Reilly, O. Melander, P.M. Mannucci, D. Ardissino, D. Siscovick, R. Elosua, K. Stefansson, C.J. O'Donnell, V. Salomaa, D.J. Rader, L. Peltonen, S.M. Schwartz, D. Altshuler, S. Kathiresan, Plasma HDL cholesterol and risk of myocardial infarction: a mendelian randomisation study, Lancet. 2012; 380: 572-580

11) M.L. Bots, F.L. Visseren, G.W. Evans, W.A. Riley, J.H. Revkin, C.H. Tegeler, C.L. Shear, W.T. Duggan, R.M. Vicari, D.E. Grobbee, J.J. Kastelein, R. Investigators, Torcetrapib and carotid intima-media thickness in mixed dyslipidaemia (RADIANCE 2 study): a randomised, double-blind trial, Lancet. 2007; 370: 153-160

12) P. Barter, J. Kastelein, A. Nunn, R. Hobbs, B. Future Forum Editorial, High density lipoproteins (HDLs) and atherosclerosis; the unanswered questions, Atherosclerosis. 2003; 168: 195-211

13) E. Tiozzo, H. Gardener, B.I. Hudson, C. Dong, D. DellaMorte, M. Crisby, R.B. Goldberg, M.S. Elkind, Y.K. Cheung, C.B. Wright, R.L. Sacco, T. Rundek, High-density lipoprotein subfractions and carotid plaque: the Northern Manhattan Study, Atherosclerosis. 2014; 237: 163-168

14) L. Calabresi, G. Franceschini, M. Sirtori, G. Gianfranceschi, P. Werba, C.R. Sirtori, Influence of serum triglycerides on the HDL pattern in normal subjects and patients with coronary artery disease, Atherosclerosis. 1990; 84: 41-48

15) J.T. Salonen, R. Salonen, K. Seppanen, R. Rauramaa, J. Tuomilehto, HDL, HDL2, and HDL3 subfractions, and the risk of acute myocardial infarction. A prospective population study in eastern Finnish men, Circulation. 1991; 84: 129-139 
16) C.M. Smuts, H.F. Weich, M.J. Weight, M. Faber, M. Kruger, C.J. Lombard, A.J. Benade, Free cholesterol concentrations in the high-density lipoprotein subfraction-3 as a risk indicator in patients with angiographically documented coronary artery disease, Coron Artery Dis. 1994; 5: 331-338

17) H.R. Superko, L. Pendyala, P.T. Williams, K.M. Momary, S.B. King, 3rd, B.C. Garrett, High-density lipoprotein subclasses and their relationship to cardiovascular disease, J Clin Lipidol. 2012; 6: 496-523

18) P.N. Demacker, H.L. Hak-Lemmers, A.G. Hijmans, H. Baadenhuysen, Evaluation of the dual-precipitation method for determination of cholesterol in high-density lipoprotein subfractions HDL2 and HDL3 in serum, Clin Chem. 1986; 32: 819-825

19) W. Patsch, S.A. Brown, J.D. Morrisett, A.M. Gotto, Jr., J.R. Patsch, A dual-precipitation method evaluated for measurement of cholesterol in high-density lipoprotein subfractions HDL2 and HDL3 in human plasma, Clin Chem. 1989; 35: 265-270

20) G.R. Warnick, M. Nauck, N. Rifai, Evolution of methods for measurement of HDL-cholesterol: from ultracentrifugation to homogeneous assays, Clin Chem. 2001; 47: $1579-1596$

21) T. Hirano, K. Nohtomi, S. Koba, A. Muroi, Y. Ito, A simple and precise method for measuring HDL-cholesterol subfractions by a single precipitation followed by homogenous HDL-cholesterol assay, J Lipid Res. 2008; 49: 1130-1136

22) Y. Katayama, H. Sugiuchi, K. Matsushima. Method for measuring cholesterol in HDL subfraction, and reagents and kit therefore, U.S. Patent. 2015; 9: 080,201 B2

23) Y. Notsu, S. Yano, H. Shibata, A. Nagai, T. Nabika, Plasma arginine/ADMA ratio as a sensitive risk marker for atherosclerosis: Shimane CoHRE study, Atherosclerosis. 2015; 239: 61-66

24) S. Yano, A. Nagai, M. Isomura, M. Yamasaki, T. Kijima, M. Takeda, T. Hamano, T. Nabika, Relationship between Blood Myostatin Levels and Kidney Function: Shimane CoHRE Study, PLoS One. 2015; 10: e0141035

25) D.M. Burns, Epidemiology of smoking-induced cardiovascular diseases, Prog Cardiovasc Dis. 2003; 46: 11-29

26) E. Imai, M. Horio, K. Nitta, K. Yamagata, K. Iseki, S. Hara, N. Ura, Y. Kiyohara, H. Hirakata, T. Watanabe, T. Moriyama, Y. Ando, D. Inaguma, I. Narita, H. Iso, K. Wakai, Y. Yasuda, Y. Tsukamoto, S. Ito, H. Makino, A. Hishida, S. Matsuo, Estimation of glomerular filtration rate by the MDRD study equation modified for Japanese patients with chronic kidney disease, Clin Exp Nephrol. 2007; 11: 41-50

27) T.J. Bronzert, H.B. Brewer Jr, New micromethod for measuring cholesterol in plasma lipoprotein fractions, Clin Chem. 1997; 23: 2089-2098

28) R.J. Havel, H.A. Eder, J.H. Bragdon, The distribution and chemical composition of ultracentrifugally separated lipoproteins in human serum, J Clin Invest. 1955; 34: $1345-1353$

29) T. Hirano, K. Nohtomi, S. Koba, A. Muroi, Y. Ito, A simple and precise method for measuring HDL-cholesterol subfractions by a single precipitation followed by homogenous HDL-cholesterol assay, J Lipid Res. 2008; 49:
1130-1136

30) J.F. Polak, M.J. Pencina, K.M. Pencina, C.J. O'Donnell, P.A. Wolf, R.B. D'Agostino, Sr., Carotid-wall intimamedia thickness and cardiovascular events, N Engl J Med. 2011; 365: 213-221

31) J.F. Polak, M. Szklo, R.A. Kronmal, G.L. Burke, S. Shea, A.E. Zavodni, D.H. O'Leary, The value of carotid artery plaque and intima-media thickness for incident cardiovascular disease: the multi-ethnic study of atherosclerosis, J Am Heart Assoc. 2013; 2: e000087

32) D. Baldassarre, A. Hamsten, F. Veglia, U. de Faire, S.E. Humphries, A.J. Smit, P. Giral, S. Kurl, R. Rauramaa, E. Mannarino, E. Grossi, R. Paoletti, E. Tremoli, I.S. Group, Measurements of carotid intima-media thickness and of interadventitia common carotid diameter improve prediction of cardiovascular events: results of the IMPROVE (Carotid Intima Media Thickness [IMT] and IMT-Progression as Predictors of Vascular Events in a High Risk European Population) study, J Am Coll Cardiol. 2012; 60: 1489-1499

33) P.J. Barter, M. Caulfield, M. Eriksson, S.M. Grundy, J.J. Kastelein, M. Komajda, J. Lopez-Sendon, L. Mosca, J.C. Tardif, D.D. Waters, C.L. Shear, J.H. Revkin, K.A. Buhr, M.R. Fisher, A.R. Tall, B. Brewer, I. Investigators, Effects of torcetrapib in patients at high risk for coronary events, N Engl J Med. 2007; 357: 2109-2122

34) G.G. Schwartz, A.G. Olsson, C.M. Ballantyne, P.J. Barter, I.M. Holme, D. Kallend, L.A. Leiter, E. Leitersdorf, J.J. McMurray, P.K. Shah, J.C. Tardif, B.R. Chaitman, R. Duttlinger-Maddux, J. Mathieson, O.C. dal, Investigators, Rationale and design of the dal-OUTCOMES trial: efficacy and safety of dalcetrapib in patients with recent acute coronary syndrome, Am Heart J. 2009; 158: 896901.e3

35) A.-H. Investigators, W.E. Boden, J.L. Probstfield, T. Anderson, B.R. Chaitman, P. Desvignes-Nickens, K. Koprowicz, R. McBride, K. Teo, W. Weintraub, Niacin in patients with low HDL cholesterol levels receiving intensive statin therapy, N Engl J Med. 2011; 365: 2255-2267

36) V. Atger, P. Giral, A. Simon, M. Cambillau, J. Levenson, J. Gariepy, J.L. Megnien, N. Moatti, High-density lipoprotein subfractions as markers of early atherosclerosis. PCVMETRA Group. Prevention Cardio-Vasculaire en Medecene du Travail, Am J Cardiol. 1995; 75: 127-131

37) H. Drexel, J. Steurer, J. Muntwyler, S. Meienberg, H.R. Schmid, E. Schneider, E. Grochenig, F.W. Amann, Predictors of the presence and extent of peripheral arterial occlusive disease, Circulation. 1996; 94: Suppl9 II 199205

38) H.J. Kempen, C.M. van Gent, R. Buytenhek, B. Buis, Association of cholesterol concentrations in low-density lipoprotein, high-density lipoprotein, and high-density lipoprotein subfractions, and of apolipoproteins AI and AII, with coronary stenosis and left ventricular function, J Lab Clin Med. 1987; 109: 19-26

39) S.S. Martin, A.A. Khokhar, H.T. May, K.R. Kulkarni, M.J. Blaha, P.H. Joshi, P.P. Toth, J.B. Muhlestein, J.L. Anderson, S. Knight, Y. Li, J.A. Spertus, S.R. Jones, C. Lipoprotein Investigators, HDL cholesterol subclasses, myocardial infarction, and mortality in secondary prevention: the Lipoprotein Investigators Collaborative, Eur 
Heart J. 2015; 36: 22-30

40) J.J. Albers, A. Slee, J.L. Fleg, K.D. O'Brien, S.M. Marcovina, Relationship of baseline HDL subclasses, small dense LDL and LDL triglyceride to cardiovascular events in the AIM-HIGH clinical trial, Atherosclerosis. 2016; 251: 454-459

41) P.H. Joshi, P.P. Toth, S.T. Lirette, M.E. Griswold, J.M. Massaro, S.S. Martin, M.J. Blaha, K.R. Kulkarni, A.A. Khokhar, A. Correa, R.B. D'Agustino, Sr., S.R. Jones, G. Lipoprotein Investigators Collaborative Study, Association of high-density lipoprotein subclasses and incident coronary heart disease: The Jackson Heart and Framingham Offspring Cohort Studies, Eur J Prev Cardiol. 2016; 23: 41-49

42) B. Foger, G. Luef, A. Ritsch, C. Schmidauer, A. Doblinger, M. Lechleitner, F. Aichner, J.R. Patsch, Relationship of high-density lipoprotein subfractions and cholesteryl ester transfer protein in plasma to carotid artery wall thickness, J Mol Med (Berl). 1995; 73: 369-372

43) P. Giral, V. Atger, J. Amar, M. Cambillau, M. Del Pino, J.L. Megnien, J. Levenson, N. Moatti, A. Simon, A relationship between aortic stiffness and serum HDL3 cholesterol concentrations in hypercholesterolaemic, symptom-free men. The PCVMETRA Group (Groupe de Prevention Cardiovasculaire en Medecine du Travail), J Cardiovasc Risk. 1994; 1: 53-58

44) N.E. Miller, F. Hammett, S. Saltissi, S. Rao, H. van Zeller, J. Coltart, B. Lewis, Relation of angiographically defined coronary artery disease to plasma lipoprotein subfractions and apolipoproteins, Br Med J (Clin Res Ed). 1981; 282: 1741-1744

45) E. Tiozzo, H. Gardener, B.I. Hudson, C. Dong, D. DellaMorte, M. Crisby, R.B. Goldberg, M.S. Elkind, Y.K. Cheung, C.B. Wright, R.L. Sacco, M. Desvarieux, T. Rundek, Subfractions of High-Density Lipoprotein-Cholesterol and Carotid Intima-Media Thickness: The Northern Manhattan Study, Stroke. 2016; 47: 1508-1513

46) J.J. Li, Y. Zhang, S. Li, C.J. Cui, C.G. Zhu, Y.L. Guo, N.Q. Wu, R.X. Xu, G. Liu, Q. Dong, J. Sun, Large HDL Subfraction But Not HDL-C Is Closely Linked With Risk Factors, Coronary Severity and Outcomes in a Cohort of Nontreated Patients With Stable Coronary Artery Disease: A Prospective Observational Study, Medicine (Baltimore). 2016; 95: e2600

47) T.W. Wu, C.L. Hung, C.C. Liu, Y.J. Wu, L.Y. Wang, H.I. Yeh, Association of cardiovascular risk factors with carotid intima-media thickness in middle-age adults and elders. J Atheroscler Thromb. 2017; 24: 677-686

48) A. Hirata, T. Okamura, D. Sugiyama, K. Kuwabara, A. Kadota, A. Fujiyoshi, K. Miura, N. Okuda, T. Ohkubo, A. Okayama, H. Ueshima; NIPPON DATA90 Research Group. The relationship between very high levels of serum high-density lipoprotein cholesterol and cause-specific mortality in a 20-year follow-up study of Japanese general population, J Atheroscler Thromb. 2016; 23: 800809

49) Y. Sunami, M. Motoyama, F. Kinoshita, Y. Mizooka, K. Sueta, A. Matsunaga, J. Sasaki, H. Tanaka, M. Shindo, Effects of low-intensity aerobic training on the high-density lipoprotein cholesterol concentration in healthy elderly subjects, Metabolism. 1999; 48: 984-988
50) M.C. Mahaney, J. Blangero, D.L. Rainwater, G.E. Mott, A.G. Comuzzie, J.W. MacCluer, J.L. VandeBerg, Pleiotropy and genotype by diet interaction in a baboon model for atherosclerosis: a multivariate quantitative genetic analysis of HDL subfractions in two dietary environments, Arterioscler Thromb Vasc Biol. 1999; 19: 11341141

51) M.W. Baumstark, I. Frey, A. Berg, J. Keul, Influence of n-3 fatty acids from fish oils on concentration of highand low-density lipoprotein subfractions and their lipid and apolipoprotein composition, Clin Biochem. 1992; 25: $338-340$

52) M. Teran-Garcia, J.P. Despres, C. Couillard, A. Tremblay, C. Bouchard, Effects of long-term overfeeding on plasma lipoprotein levels in identical twins, Atherosclerosis. 2004; 173: $277-283$

53) A. Zambon, S.S. Deeb, J.E. Hokanson, B.G. Brown, J.D. Brunzell, Common variants in the promoter of the hepatic lipase gene are associated with lower levels of hepatic lipase activity, buoyant LDL, and higher HDL2 cholesterol, Arterioscler Thromb Vasc Biol. 1998; 18: 17231729

54) M.C. Carr, A.F. Ayyobi, S.J. Murdoch, S.S. Deeb, J.D. Brunzell, Contribution of hepatic lipase, lipoprotein lipase, and cholesteryl ester transfer protein to LDL and HDL heterogeneity in healthy women, Arterioscler Thromb Vasc Biol. 2002; 22: 667-673

55) L.E. Bakker, M.R. Boon, W. Annema, A. Dikkers, H.J. van Eyk, A. Verhoeven, O.A. Mayboroda, J.W. Jukema, L.M. Havekes, A.E. Meinders, K. Willems van Dijk, I.M. Jazet, U.J. Tietge, P.C. Rensen, HDL functionality in South Asians as compared to white Caucasians, Nutr Metab Cardiovasc Dis. 2016; 26: 697-705

56) D.L. Fulton-Kehoe, R.H. Eckel, S.M. Shetterly, R.F. Hamman, Determinants of total high density lipoprotein cholesterol and high density lipoprotein subfraction levels among Hispanic and non-Hispanic white persons with normal glucose tolerance: the San Luis Valley Diabetes Study, J Clin Epidemiol. 1992; 45: 1191-1200

57) W.H. Ettinger, Jr., R.B. Verdery, P.W. Wahl, L.P. Fried, High density lipoprotein cholesterol subfractions in older people, J Gerontol. 1994; 49: M116-122

58) A.V. Khera, M. Cuchel, M. de la Llera-Moya, A. Rodrigues, M.F. Burke, K. Jafri, B.C. French, J.A. Phillips, M.L. Mucksavage, R.L. Wilensky, E.R. Mohler, G.H. Rothblat, D.J. Rader, Cholesterol efflux capacity, highdensity lipoprotein function, and atherosclerosis, N Engl J Med. 2011; 364: 127-135

59) A. Rohatgi, A. Khera, J.D. Berry, E.G. Givens, C.R. Ayers, K.E. Wedin, I.J. Neeland, I.S. Yuhanna, D.R. Rader, J.A. de Lemos, P.W. Shaul, HDL cholesterol efflux capacity and incident cardiovascular events, N Engl J Med. 2014; 371: 2383-2393

60) D. Saleheen, R. Scott, S. Javad, W. Zhao, A. Rodrigues, A. Picataggi, D. Lukmanova, M.L. Mucksavage, R. Luben, J. Billheimer, J.J. Kastelein, S.M. Boekholdt, K.T. Khaw, N. Wareham, D.J. Rader, Association of HDL cholesterol efflux capacity with incident coronary heart disease events: a prospective case-control study, Lancet Diabetes Endocrinol. 2015; 3: 507-513 
HDL3-C

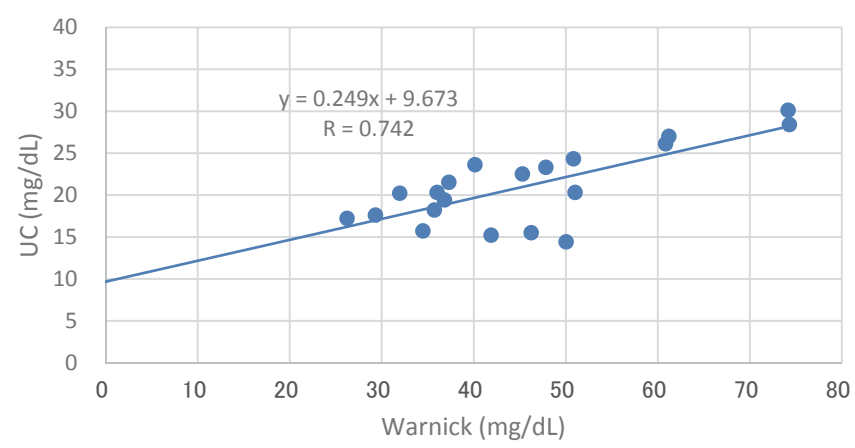

HDL3-C

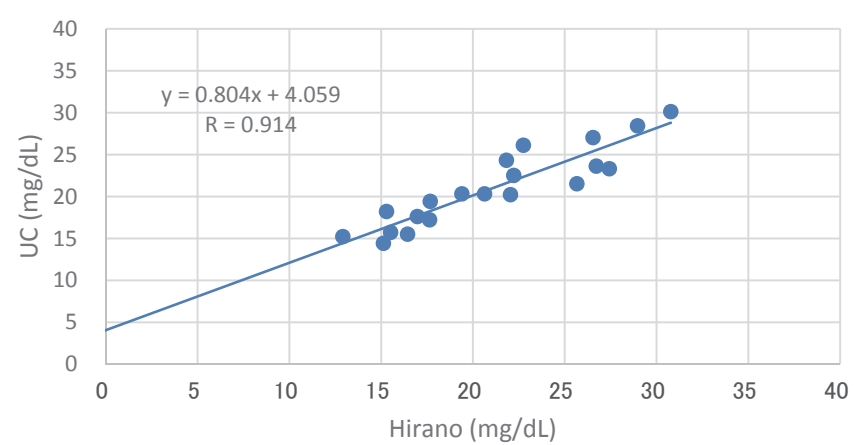

HDL2-C

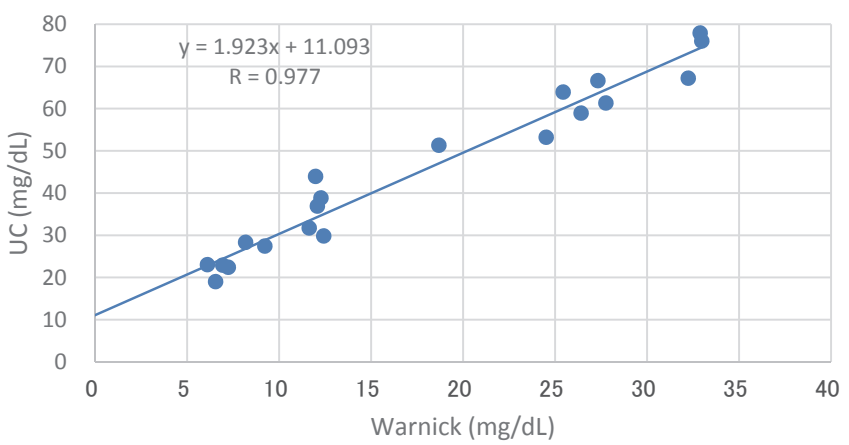

HDL2-C

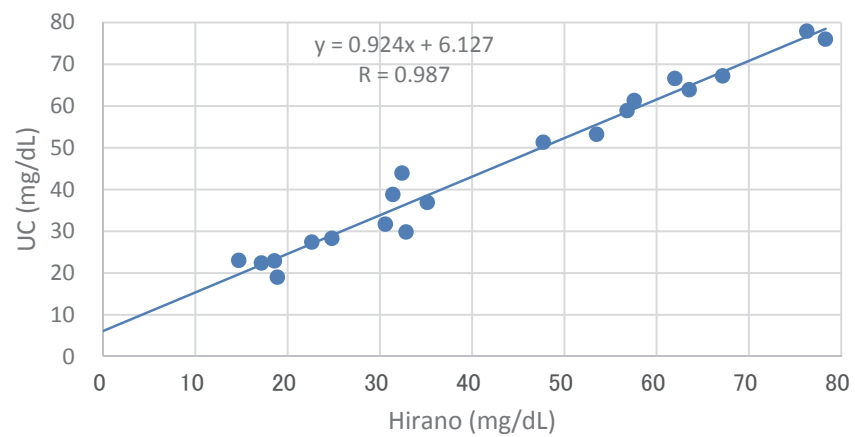

Supplementary Fig. 1. Correlation between HDL-C subclasses determined by the Warnick and Hirano methods and by ultracentrifugation (UC). 